\title{
Imagens e significado e o processamento dos estereótipos ${ }^{1}$
}

\author{
Marcos Emanoel Pereira \\ Universidade Federal da Bahia \\ Fernanda de Oliveira Ferreira \\ Aretha Henrique Martins \\ Cleciane Morosino Cupertino \\ Universidade Federal de Juiz de Fora
}

\begin{abstract}
Resumo
Este trabalho avaliou a influência da representação do conhecimento mediante significados e imagens no processamento dos estereótipos. Utilizando a escala de distância social de Bogardus, procurou-se determinar se a avaliação de uma categoria alvo, realizada por meio da simples apresentação do rótulo verbal da categoria, diferia de uma avaliação em que se acrescentava, durante a apresentação, uma fotografia de exemplares típicos de cada categoria. Um segundo foco de interesse procurou determinar os efeitos contextuais na avaliação dos estereótipos, no caso, a influência do tamanho da cidade de residência do participante na avaliação da distância social. Os resultados apontaram diferenças significativas na avaliação da categoria alvo quando apresentada por meio de estímulos inteiramente abstratos, se comparada com a avaliação realizada quando foram acrescentadas fotografias de exemplares do grupo alvo. Além disso, o tamanho da cidade de residência do participante influenciou o grau de distância social em relação aos membros da categoria alvo.
\end{abstract}

Palavras-chave: Estereótipos, Imagens, Significados, Distância social.

\begin{abstract}
Images and meanings in stereotyping. This article intends to evaluate the influence of two basic forms of representation of knowledge, through meanings and through images, in the process of creating stereotypes. By adopting a modified version of Bogardus's scale of distance, it seeks to determine whether the evaluation of a target category, through a simple presentation of the verbal label of it, differs from another evaluation, in which is added, during its presentation, a photograph of a typical sample of the mentioned category. A second focus of interest tries to determine the influence of contextual effects on the evaluation of stereotypes. The aspect chosen here is the influence of the size of city on the participant evaluation of social distance. The results point out a remarkable difference in the evaluation of the target category when participants were exposed to entirely abstract stimuli, compared to when photos of examples from the target group were added to it. In regard to size of city, this study concluded that it has a vivid influence on the degree of social distance of the participants in relation to members of the target category. It presents also some considerations on the utilization of semantic priming in contemporary experimental research about stereotypes.
\end{abstract}

Key words: Stereotypes, Stereotyping, Images, Meanings.

I nexoravelmente, a caracterização de qualquer disciplina científica depende da presença de três elementos fundamentais: objeto, métodos e matrizes teóricas. Decerto, a ciência pode ser considerada um empreendimento dinâmico, podendo-se esperar uma relação de interdependência entre esses elementos, algo que se observa, embora nem sempre de forma explícita, nos domínios da psicologia. Na psicologia social, o estudo dos estereótipos evidencia esta tendência de forma clara, a se considerar, por exemplo, as relações entre definição dos estereótipos e os métodos de investigação. Em um primeiro momento, quando os estereótipos eram caracterizados sobretudo como crenças compartilhadas pelos percebedores, os métodos se voltavam, prioritariamente, para a identificação dos conteúdos dos estereótipos, principalmente mediante estratégias de auto-relato. Posteriormente, no momento em que é estabelecida a diferenciação entre os 
estereótipos enquanto crenças compartilhadas e o processo de estereotipização (Gaskell \& Fraser, 1990; Macrae, Stangor \& Hewstone, 1996), os métodos se adequaram a esta nova definição e se voltaram para o esclarecimento, por meio de procedimentos experimentais, do papel dos mediadores cognitivos envolvidos no processo de estereotipização (Hamilton, Stroessner \& Driscoll, 1994).

Atualmente, embora o predomínio dos métodos experimentais seja evidente, tal hegemonia não significou o completo abandono dos métodos de auto-relatos, tampouco que eles tenham passado a ocupar uma posição secundária. Decerto, os investigadores continuam a utilizar tanto os métodos diretos, quanto os métodos indiretos de investigação, observando-se, nas pesquisas contemporâneas sobre os estereótipos, uma forte tendência no sentido de se utilizar conjuntamente estratégias de investigação que articulam os métodos de auto-relato e os experimentais, o que parece ser uma postura conveniente tendo em vista a natureza complexa do objeto de estudo.

Os métodos diretos, centrados principalmente em estratégias de obtenção de dados por meio de auto-relato, moldaram o campo de estudos dos estereótipos, sobretudo com a introdução da técnica do checklist, após a publicação da pesquisa original de Katz e Braly (1933) e as suas posteriores réplicas (Gilbert, 1951; Karlins, Coffman \& Walters, 1969), no que se convencionou denominar 'a trilogia de Princeton'. Posteriormente, em decorrência das críticas apresentadas contra a técnica adotada nessas investigações, foram introduzidos vários aperfeiçoamentos, tais como o método das percentagens (Brigham, 1971) e o da razão diagnóstica (McCauley \& Stitt, 1978) que, em última instância, procuraram reduzir o impacto das críticas iniciais. Apesar do seu acentuado predomínio, essa técnica não se consubstanciou como a única alternativa encontrada pelos psicólogos sociais da primeira metade do século XX. Tomando como ponto de partida o trabalho seminal de Lippman (1922), que definiu os estereótipos como fotografias na cabeça do percebedor, um outro método, denominado pictórico, utilizava imagens fotográficas de indivíduos de várias categorias sociais para investigar os estereótipos. O princípio básico das investigações orientadas pelo método pictórico consistia no entendimento de que, se a imagem de um indivíduo de uma determinada categoria social fosse identificada em uma proporção maior do que a esperada por acaso como característica desse grupo, poder-se-ia imaginar a presença do estereótipo. Além destes dois, um outro método importante de estudo de estereótipos mediante estratégias de auto-relato contemplava o uso de escalas de atitudes, o que significava, evidentemente, privilegiar a dimensão avaliativa dos estereótipos. A escala de distância social de Bogardus é um exemplo bastante claro desta tendência e, embora não tenha sido deliberadamente desenvolvida para a investigação dos estereótipos, mas sim de preconceitos, o seu uso é facultado, desde que se assuma que os estereótipos podem ser inferidos a partir do nível de preconceito apresentado explicitamente pelo percebedor.

A partir dos anos 60, com o predomínio do cognitivismo na psicologia e da perspectiva da cognição social na psicolo- gia social, observou-se uma mudança acentuada no interesse dos investigadores dos estereótipos. Brigham (1971), um dos primeiros a chamar a atenção para esta nova tendência, observou que algumas décadas de estudos foram insuficientes para permitir o surgimento de pesquisas voltadas para a determinação dos processos envolvidos na ativação e na aplicação dos estereótipos. De fato, apenas em meados dos anos 80 , os estereótipos foram definidos de uma forma mais compatível com a abordagem cognitivista, passando a ser concebidos como estruturas que contém o conhecimento, as crenças e as expectativas do percebedor em relação a algum grupo humano (Hamilton \& Trolier, 1986). Em conseqüência dessa mudança no plano conceitual, observou-se o surgimento de uma nova direção de trabalho, com a procura da determinação dos conteúdos dos estereótipos tendo sido colocada em um segundo plano e a busca do entendimento de como os estereótipos influenciam a percepção social, o julgamento e o comportamento passando a ocupar uma posição destacada (Hilton \& Von Hippel, 1996). A partir de então, reconheceu-se claramente a necessidade de determinar como os estereótipos conseguem influenciar a maior parte do processamento das informações sociais, incluindo a alocação da atenção, a interpretação dos comportamentos, a elaboração de inferências, a busca de informações e a seleção do tipo de informação a ser recuperada da memória (Sherman, 1996).

Em meados da década de 90, os estereótipos passaram a ser considerados crenças compartilhadas referentes aos atributos pessoais, especialmente traços de personalidade e aos comportamentos de um grupo de pessoas, enquanto a estereotipização foi definida como o processo de aplicar um julgamento estereotipado a um indivíduo de forma a apresentálo como tendo traços intercambiáveis com outros membros de uma mesma categoria (Leyens, Yzerbyt \& Schadron, 1994). Após essa mudança na definição dos estereótipos seguiuse, evidentemente, uma transformação nos métodos de investigação. A principal delas referiu-se à utilização acentuada do priming como meio para a manipulação das variáveis independentes e da adoção de medidas de tempo de reação e de decisão lexical como recursos para a mensuração da variável dependente. Os efeitos do priming nos processos cognitivos foram analisados detalhadamente por Fiske (1998), onde podem ser encontrados argumentos consistentes com o ponto de vista de que o priming favorece a avaliação positiva do ingroup, facilita a associação entre categorias e estereótipos e contribui para o processo de categorização.

As diversas tentativas de identificar as estruturas cognitivas envolvidas na manifestação dos estereótipos realizaram-se de acordo com os desenvolvimentos oriundos da psicologia cognitiva, sendo especialmente importante a relevância atribuída às representações mentais constituídas a partir dos esquemas, protótipos e exemplares (Stangor \& Schaller, 1996). Os modelos abstratos supõem a presença de um conjunto de representações dos fatores típicos do objeto, representações estas fundadas nas experiências com exemplares do grupo ou na aprendizagem com agentes externos, enquanto os modelos centrados em exemplares supõem a existência de representações armazenadas independentemente 
na memória para cada um dos exemplares ao qual se esteve exposto. Os psicólogos sociais tradicionalmente adotam os modelos abstratos, com as generalizações sendo tratadas em termos de conceitos como os de esquemas ou protótipos. Apesar das suas evidentes diferenças, esses dois conceitos supõem que os estereótipos sejam representados como um conjunto abstrato de fatores típicos de um grupo social e, embora admitam que a informação presente na base dos estereótipos tenha sido aprendida através da experiência com as pessoas e grupos, muitos psicólogos sustentam que após a formação dos estereótipos, uma representação abstrata dos mesmos é armazenada na memória em um local diferente daquele destinado à armazenagem dos exemplares que lhes deram origem.

Em decorrência das divergências encontradas nas explicações oferecidas por cada uma dessas abordagens, muitos autores sugeriram a adoção de um modelo misto, que levasse em consideração tanto as representações abstratas quanto as informações que se apresentam por meio de exemplares (Sherman, 1996; Stangor, 2000). De acordo com este novo entendimento, a representação mental dos estereótipos dependeria da quantidade de experiência do percebedor com o grupo objeto do estereótipo, de forma que em um primeiro momento, com o conhecimento do grupo ainda rudimentar, as informações estariam relacionadas, em grande medida, aos exemplares com os quais os percebedores mantiveram algum contato. Contudo, com a intensificação do conhecimento sobre a categoria alvo, seriam construídas representações abstratas que serviriam como ponto de partida para a formação dos estereótipos sobre os grupos e, uma vez desenvolvidas, elas constituiriam a base para o posterior processamento dos estereótipos. Em conseqüência dessa formulação, podese afirmar que os estereótipos baseados em exemplares manifestam-se enquanto não é formada uma representação abstrata dos mesmos, mas assim que isso ocorre o processamento dos estereótipos pode prescindir e realiza-se independentemente dos exemplares armazenados na memória.

Conquanto tenham sido identificados grandes avanços a respeito de como os grupos são mentalmente representados (Wyer \& Srull, Jr., 1986), muitas questões ainda permanecem em aberto, solicitando novas investigações. Um problema pouco discutido refere-se à diferença dos efeitos das diversas modalidades de representação do conhecimento sobre os grupos no processo de estereotipização. Partindo-se do postulado da existência de um código dual, em que o conhecimento pode ser representado tanto sob a forma de imagens quanto sob a forma de significados (Anderson, 2000; Eysenck \& Keane, 1994), parece importante identificar o papel desempenhado por esses dois códigos no processo de estereotipização (Macrae, Bodenhausen, Milne \& Calvini, 1999), podendo-se perguntar, por exemplo, se em uma tarefa que envolve a avaliação de uma série de categorias for acrescentada uma representação pictórica de um exemplar do grupo a ser avaliado, tal acréscimo provocaria alguma diferença na avaliação das diversas categorias. Essa questão é importante porque se for aceito o ponto de vista de que os efeitos das representações verbais e pictóricas são semelhantes, poder-se-ia supor, conseqüentemente, uma equivalência entre os rótulos verbais e as pessoas reais, o que autorizaria os investigadores a utilizarem despreocupadamente o priming semântico como recurso para avaliação dos membros do grupo alvo. Se esta equivalência, no entanto, não se justificar, pode ser necessário modificar os procedimentos experimentais, no sentido de tornar a apresentação dos estímulos mais compatível com os padrões de contatos estabelecidos com pessoas reais.

Ao se reconhecer que os efeitos tanto da homogeneidade na avaliação dos outgroups quanto do etnocentrismo exercem considerável influência no âmbito das relações intergrupais (Brauer, 2001), parece ser importante tratar o problema do erro fundamental na avaliação de ingroups e outgroups. $\mathrm{O}$ erro fundamental sugere a presença, em todo percebedor, de uma clara tendência no sentido de maximizar as diferenças intergrupais e de minimizar as diferenças intragrupais (Brown \& Turner, 1989; Messick \& Mackie, 1989). Se durante a apresentação dos estímulos de uma categoria alvo a ser avaliada for acrescentado um componente pictórico capaz de evidenciar que os membros de uma dada categoria se assemelham, no plano físico, aos membros da categoria do grupo da pessoa que está julgando, pode-se imaginar, portanto, uma redução do estereótipo, esperando-se, em contrapartida, uma tendência, por parte do percebedor, a intensificar o julgamento estereotipado no caso de categorias sociais fisicamente muito diferentes da sua, se à apresentação da categoria a partir do significado for acrescentado um componente pictórico.

Um outro problema teórico que permanece em aberto e que este estudo procura se aproximar refere-se a uma dimensão contextual, relacionando-se com o tamanho da cidade em que o percebedor reside. Neste caso, levando adiante os argumentos apresentados pelos defensores da hipótese do contato como critério para o aperfeiçoamento das relações intergrupais (Petigrew, 2000; Stephen \& Stephen, 1985), podese postular que habitantes de cidades de maior porte, por estarem sujeitos a um número maior de informações e por viverem em um meio mais cosmopolita, com acesso a tipos diferentes de pessoas durante os seus contatos interpessoais, tenderão a realizar julgamentos menos estereotipados que os residentes em cidades de menor porte.

\section{Hipóteses}

A primeira hipótese deste trabalho refere-se à avaliação diferencial das categorias sociais. Levando em consideração que as 12 categorias sociais incluídas neste estudo (americanos, alemães, aborígines australianos, nigerianos, jogador de futebol, argentino, muçulmano, judeu, indígena, esquimó, punk, japonês) são representadas de uma forma bastante distinta, é possível postular que a avaliação destes diversos grupos em termos de distância social será bastante heterogênea, podendo-se supor, ainda, que algumas categorias, em decorrência do prestígio econômico e político desfrutado (americanos, alemães, japoneses) serão avaliadas de uma forma bem mais positiva que as categorias sociais com as quais 
o contato é reduzido (aborígines australianos e esquimós), com que se observa alguma rivalidade (argentinos) ou que são francamente outsiders (punks).

A segunda hipótese assevera que as categorias sociais mais parecidas com o grupo dos avaliadores, seja em termos de traços físicos ou de trajes, tenderão a ser avaliadas de uma forma mais positiva na condição em que se apresenta a foto com um exemplar da categoria avaliada do que na condição em que a categoria é apenas referida por critérios lingüísticos. Desta forma, espera-se que a avaliação de alemães, americanos, japoneses, argentinos e judeus seja mais positiva na condição em que a foto é apresentada do que na condição em que a fotografia não é apresentada.

A terceira hipótese sugere que as categorias sociais menos parecidas com o grupo dos avaliadores, tanto em termos de traços físicos quanto de trajes, tenderão a ser avaliadas de uma forma mais negativa na condição em que se apresenta a foto com um exemplar da categoria avaliada que na condição em que a categoria é apenas referida por critérios linguísticos. Desta forma, espera-se que a avaliação de aborígines australianos, indígenas, nigerianos, punks, muçulmanos e esquimós seja mais negativa na condição em que a foto é apresentada do que na condição oposta.

A quarta e última hipótese refere-se à relação entre o tamanho da cidade e o grau de avaliação das categorias sociais. Como se pode supor que o morador de uma cidade de maior porte avalie de uma forma menos preconceituosa e estereotipada as diversas categorias sociais, espera-se que a avaliação feita pelos residentes das cidades de Juiz de Fora (447.141 habitantes) e de Vila Velha (344.935 habitantes) sejam bastante semelhantes entre si, já que estas duas cidades são aproximadamente do mesmo tamanho, ao mesmo tempo em que se espera que a avaliação feita pelos residentes da cidade de Além Paraíba (33.582 habitantes) seja mais negativa, uma vez que esta cidade é de tamanho bem mais reduzido que as duas primeiras.

\section{Métodos}

Nesta seção serão descritos os participantes, os procedimentos, os instrumentos e equipamentos utilizados durante a investigação, assim como os testes estatísticos adotados para as análises dos dados.

\section{Participantes}

Este estudo contou com a colaboração de 206 participantes, dos quais 101 (49\%) declararam-se do sexo masculino e $105(51 \%)$ do sexo feminino. A média de idade dos participantes foi de 25,7 anos (desvio-padrão = 9,31; mediana $=22$ anos; moda $=18$ anos; mínimo $=13$ anos; máximo $=67$ anos $)$. À época da investigação, $80(38,9 \%)$ participantes residiam na cidade de Juiz de Fora, MG, 66 (32\%) na cidade de Além Paraíba, MG e $60(29,1 \%)$ na cidade de Vila Velha, ES.

\section{Procedimentos}

Toda a coleta de dados foi realizada mediante procedimentos computadorizados. O participante era abordado por um auxiliar do experimentador, e sua colaboração era solicitada; caso fosse concedida, o participante era conduzido pelo auxiliar a um local isolado onde se encontrava o experimentador e um computador com os requisitos necessários para a realização do experimento. A alocação do participante à condição experimental era determinada pelo experimentador, que alternava as condições sucessivamente.

$\mathrm{O}$ experimento foi realizado de acordo com um delineamento $2 \times 3$, em que foram manipulados, na primeira condição, os tipos de escala de distância social (sem foto x com foto), enquanto a segunda condição se referia à cidade de residência do participante (Juiz de Fora, Além Paraíba ou Vila Velha).

Os dados foram coletados entre os dias 24 de maio e 20 de junho de 2000 na cidade de Juiz de Fora, MG, entre os dias 07 e 17 de setembro de 2000 na cidade de Além Paraíba, MG, e entre os dias 08 e 22 de outubro de 2000 na cidade de Vila Velha, ES.

\section{Equipamentos e instrumentos}

Toda a coleta de dados foi realizada em um notebook Pentium $200 \mathrm{Mhz}$, rodando o sistema operacional Windows 95. A versão eletrônica da escala de distância social de Bogardus foi elaborada com o sistema de autoria Asymetrix Toolbook Instructor II, versão 5.03. A primeira tela do aplicativo apresentava as instruções genéricas:

\footnotetext{
Nas próximas telas serão apresentados os nomes de alguns grupos sociais e você deverá indicar o grau de intimidade que admitiria estabelecer com algum membro do grupo mencionado. Lembre-se, no entanto, que se trata da avaliação em relação a pessoas genéricas pertencentes a estes grupos e não em relação ao melhor ou ao pior membro do grupo que você conheceu.
}

Posteriormente, nas telas seguintes o participante deveria escolher uma das seguintes alternativas em relação as 12 categorias sociais incluídas no estudo: 1) aceitaria que casasse com alguém da minha família; 2) aceitaria, como amigo, no clube que freqüento; 3) aceitaria na minha rua como vizinho; 4) aceitaria em meu país, exercendo a mesma profissão que a minha; 5) aceitaria como cidadão em meu país; 6) aceitaria que visitasse o meu país. As categorias sociais foram apresentadas na seguinte ordem: japonês, nigeriano, argentino, aborígine australiano, judeu, alemão, jogador de futebol, esquimó, indígena, muçulmano, punk e norte-americano. Após a escolha, o próprio software solicitava ao participante que justificasse a sua escolha. A seguir, o participante era convidado a declarar qual grupo, na sua opinião, seria o mais tolerado e o mais rejeitado pelos demais participantes da pesquisa. A única diferença entre as duas condições era a que na condição sem foto o grupo era referido unicamente através do rótulo verbal, enquanto na condição com foto, além do nome, era apresentada uma foto de um exemplar típico da categoria $^{2}$

\section{Estatísticas utilizadas}

Para fins de análise, os dados obtidos durante a coleta de dados foram tratados em um programa computacional de 
análises estatísticas. Em decorrência da tradição de se analisar dados de escalas psicológicas como se fossem mensurados numa escala intervalar e de alguns autores sugerirem, em contrapartida, a necessidade de se tratar os dados obtidos por meio de escalas psicológicas como se fossem mensurados em uma escala ordinal, ambos os procedimentos de análise foram executados (Morgan \& Griego, 1998). Como não foram observadas diferenças dignas de nota no nível de significância obtido entre os testes paramétricos e os não-paramétricos, os resultados serão apresentados aqui de acordo com o entendimento de que os dados foram tratados em um nível intervalar, justificando-se assim a adoção dos testes $\mathrm{t}$ de diferença entre as médias e da análise da variância.

\section{Análise e discussão dos resultados}

Não foi observada qualquer interação entre as variáveis tipo de apresentação (com foto ou sem foto) e o tamanho da cidade de residência do participante. Desta forma, serão apresentados, em separado, os resultados relativos ao teste das quatro hipóteses anteriormente apresentadas.

\section{Hipótese 1}

Observou-se uma nítida diferença na avaliação das categorias sociais incluídas neste estudo. Conforme se observa na Tabela 1, a categoria mais valorizada pelos 206 participantes foi a dos jogadores de futebol e a menos valorizada a dos punks.

Os resultados apresentados na Tabela 1 evidenciam que, dentre as categorias consideradas neste estudo, os jogadores de futebol foram avaliados da forma mais positiva, ou seja, foi a categoria em relação à qual os participantes impuseram uma menor distância social. Pode-se presumir que uma série de fatores, tais como a intensa visibilidade nos meios de comunicação de massa e o prestígio social alcançado pelos atletas de ponta possam interferir neste resultado. Além dis-

Tabela 1.

Média e desvio padrão da distância social

\begin{tabular}{lll}
\hline Categoria & Média & DP \\
Jogador de Futebol & 1,62 & 1,32 \\
Japonês & 1,91 & 1,73 \\
Alemão & 1,96 & 1,74 \\
Americano & 2,14 & 1,93 \\
Nigeriano & 2,23 & 1,78 \\
Argentino & 2,42 & 2,01 \\
Judeu & 2,44 & 1,96 \\
Indigena & 2,59 & 1,87 \\
Esquimó & 2,97 & 2,08 \\
Aborigene australiano & 3,27 & 2,07 \\
Muçulmano & 3,41 & 2,17 \\
Punk & 3,50 & 2,07
\end{tabular}

so, é inegável o papel desempenhado pelo futebol não só como meio de ascensão social para as camadas mais pobres da população, como também uma alternativa profissional para as camadas mais favorecidas, a se considerar, por exemplo, o número de escolinhas de futebol de "grife" espalhadas pelo país. Um dos participantes justificou a sua avaliação positiva em relação aos jogadores de futebol usando o argumento de que a imagem apresentada na foto "é para mim uma pessoa que parece muito comigo, em um primeiro momento, é claro" (20 anos, masculino, com foto). Outro admitiu aceitar os jogadores de futebol porque eles "têm dinheiro, viajam pelo mundo e têm um corpo bonito, além de serem famosos" (16 anos, feminino, sem foto). Embora minoria, alguns participantes apresentaram alguma rejeição em relação ao jogador de futebol com base no argumento de que eles "normalmente não possuem o grau de instrução que busco em alguém para fazer parte da minha família" (18 anos, feminino, sem foto) ou então de que se trata de "gente sem muito intelecto, não dá para conviver" (20 anos, feminino, com foto). Outras categorias bem avaliadas foram os japoneses, vistos como capacitados, pois "possuem alto grau de inteligência" (25 anos, masculino, com foto) e dedicados, já que se trata de um povo "trabalhador e honesto" (33 anos, feminino, com foto). Os alemães foram bem aceitos por se tratar de um "povo desenvolvido, iria clarear o país" (41 anos, feminino, com foto), enquanto um participante, mais explícito ainda, argumentou que o alemão seria bem aceito "para clarear a família" (23 anos, feminino, com foto). Um outro participante argumentou que "talvez pela visão de 'país desenvolvido' esse grupo será o mais aceito pela sociedade e por mim" (31 anos, masculino, sem foto). No caso dos norte-americanos, observaram-se argumentos que indicavam claramente a sua aceitação, como por exemplo, um participante que sustentou que "me amarro neles, por serem lindos" (26 anos, feminino, sem foto), ou um segundo, por que eles "têm muito dinheiro" (17 anos, masculino, com foto) ou, finalmente, um outro que conjugou os dois qualificativos apresentados nos argumentos anteriores, já que eles seriam "ricos, desenvolvidos e alguns bonitos" (16 anos, feminino, sem foto). Numa outra linha de argumento, um participante sustentou que os aceitaria muito bem, pois eles "são os donos do mundo" (33 anos, feminino, com foto). Justamente por serem considerados os 'donos do mundo', observou-se alguma rejeição aos norte-americanos. Um participante sugeriu que eles visitassem nosso país para "passar um sufoco no ônibus e trem lotado" (15 anos, masculino, com foto), enquanto outro se manifestou no sentido de sugerir que eles se mantivessem à distância porque "impedem o desenvolvimento de nosso país. Acham-se os melhores do mundo" (25 anos, masculino, com foto). De modo geral, apesar de algumas restrições, essas três últimas categorias foram bem aceitas, algo compreensível por estarem relacionadas a potências econômicas e políticas.

Ocupando posições intermediárias, encontram-se os nigerianos, os indígenas, os argentinos e os judeus. No caso dos nigerianos, um participante avaliou a categoria social como um todo a partir da sua experiência pessoal, com base 
no argumento de que "não gosto de nigerianos por motivos particulares. Conheci um que era mal-caráter (sic)" (25 anos, feminino, sem foto). Os indígenas foram relativamente bem avaliados pois, como afirmou um participante, "foram eles que iniciaram a história do país" (17 anos, feminino, sem foto). Os argumentos apresentados em relação aos argentinos foram bastante consistentes. Um sustentou que o argentino "é um italiano que fala espanhol e pensa que é inglês" (22 anos, masculino, com foto), outro argumentou que "antipáticos e arrogantes, estes nobres de sangue podre não merecem qualquer tipo de menção" (22 anos, masculino, sem foto). Alguns participantes, contudo, acenaram com uma posição mais equilibrada, como um deles que argumentou que "apesar das desavenças entre Brasil e Argentina, as relações pessoais não podem ser envolvidas nisso. Se existe um sentimento nobre entre um argentino e alguém da minha família, inclusive eu, não vai ser uma richa (sic) entre países que os farão desistir do relacionamento" (18 anos, feminino, com foto). No caso dos judeus, um participante rejeitou claramente os membros da categoria pelo fato deles possuírem o qualificativo de "não acreditar no meu senhor Jesus Cristo" (22 anos, masculino, sem foto).

Enfim, as categorias que os participantes avaliaram como aquelas que gostariam de se manter mais à distância foram os punks, muçulmanos, aborígines australianos e esquimós. No caso dos punks, eles foram considerados "violentos e preguiçosos" (50 anos, masculino, com foto), enquanto um outro participante argumentou que "não passam de meros românticos, frustrados e que na verdade utilizam aquelas vestimentas bastante chocantes com o intuito de agredir a sociedade e se esconder dentro de estereótipos" (17 anos, feminino, sem foto). Outro participante sustentou que "devido à sua ideologia racista e vândala, prefiro não ter muito contato" (20 anos, feminino, com foto). Os muçulmanos foram rejeitados sobretudo com base em argumentos religiosos. Um participante afirmou não aceitar "nem um pouco o radicalismo da religião muçulmana, acho ridículo" (20 anos, masculino, sem foto), enquanto um outro participante argumentou que "se pudesse escolheria para ele nem aparecer por aqui. Eu quero distância desse povo, acho eles muito complicados, sempre metidos em confusão" (21 anos, masculino, com foto). No caso dos aborígines australianos, houve uma rejeição claramente baseada na aparência, como no caso de um participante que sustentou que os rejeitaria "pelo jeito estranho e assustador de sua aparência", enquanto outros apresentaram argumentos claramente discriminatórios, como o caso do argumento de um participante que rejeitou claramente a categoria ao afirmar que não se trata de "uma raça normal na sociedade" (18 anos, masculino, sem foto) ou um outro que sustentou simplesmente: "não fui com a cara dele" (23 anos, feminino, com foto). Enfim, em relação aos esquimós, houve uma certa rejeição com base no argumento de que "eles não se adaptariam ao país tropical" (54 anos, feminino, sem foto).

A hipótese 1 favorece de forma clara o entendimento de que as diversas categorias são avaliadas de uma forma diferenciada, com algumas sendo tratadas com mais tolerância que outras. Os efeitos da riqueza, do prestígio e da semelhan- ça física parecem exercer uma influência nada desprezível no caso das avaliações positivas. Da mesma forma, diferenças no plano das aparências, dos trajes e de costumes parecem desempenhar uma posição digna de nota no caso das avaliações negativas (Oakes, Haslam, Morrinson \& Grace, 1995; Zebrowitz, 1996).

\section{Hipótese 2}

Esta hipótese postula que se a categoria a ser avaliada ostentar semelhanças físicas com o membro prototípico da cultura do participante, a avaliação do grupo em que se apresentou a imagem junto ao rótulo será bem mais positiva.

Conforme se observa na Tabela 2, a apresentação da fotografia não produziu qualquer diferença significativa na avaliação das categorias com características semelhantes as do percebedor. $\mathrm{O}$ teste $\mathrm{t}$ não demonstrou qualquer influência da apresentação da fotografia na avaliação de americanos, alemães, japoneses, argentinos, judeus e jogadores de futebol.

Tabela 2

Distância social das categorias na condição com foto e sem foto

\begin{tabular}{lccc|}
\hline Categoria social & sem foto & com foto & $\mathrm{p}$ \\
\hline futebol & 1,66 & 1,60 & $\mathrm{n} . \mathrm{s}$. \\
japonês & 1,80 & 2,01 & n.s. \\
alemão & 1,83 & 2,07 & n.s. \\
americano & 2,02 & 2,27 & n.s. \\
argentino & 2,30 & 2,53 & n.s. \\
judeu & 2,37 & 2,49 & n.s. \\
\hline
\end{tabular}

Ao contrário do esperado, o teste da hipótese 2 indicou que o simples fato de ver uma fotografia de uma pessoa do outgroup, por mais semelhante que tenha sido os traços físicos com a imagem prototípica do membro do grupo social do avaliador, parece ter sido insuficiente para reduzir o efeito de estereotipização ou reduzir a distância social. Estes resultados parecem compatíveis com os argumentos apresentados pelos teóricos que defendem uma concepção essencialista da categorização social (Yzerbyt, Rocher \& Schadron, 1997), em que se sustenta, tomando como ponto de partida o entendimento de que os estereótipos devem ser considerados como gestalts esclarecedoras, que a similaridade deve ser vista como uma consequiência e não como uma causa da categorização, podendo-se supor, portanto, que o critério de similaridade não parece ser suficientemente forte para produzir efeitos significativos na redução dos efeitos da estereotipização.

\section{Hipótese 3}

Esta hipótese postula que se a categoria a ser avaliada apresentar características físicas distintas daquelas tradicionalmente encontradas no membro prototípico da cultura do participante, a avaliação do grupo em que se apresentou a imagem junto ao rótulo será bem mais negativa.

Neste caso, uma fotografia apresentando uma imagem de uma pessoa não convencional, quando comparada ao pa- 
Tabela 3 .

Distância social das categorias na condição com foto e sem foto

\begin{tabular}{lccl}
\hline Categoria social & sem foto & com foto & $\mathrm{p}$ \\
punk & 2,98 & 3,96 & $*$ \\
muçulmano & 3,01 & 3,77 & $* *$ \\
indigena & 2,33 & 2,81 & $* * *$ \\
aborígine & 2,55 & 3,89 & $*$ \\
esquimó & 2,65 & 3,25 & $* *$ \\
nigeriano & 1,94 & 2,48 & $* *$ \\
\hline
\end{tabular}

Nota: $*<.001 ; * *<.05 ; * * *<.01$

drão físico imperante entre os membros da cultura dos avaliadores, produziu efeitos significativos na avaliação da distância social. Desta forma, a apresentação da imagem fotográfica gerou um acréscimo considerável na distância social, em relação às categorias dos punks $\left(2,98 \times 3,96\right.$; ${ }_{(204)}=3,49$; $\mathrm{p}=.001)$, muçulmanos $\left(3,01 \times 3,77 ; \mathrm{t}_{(204)}=2,54 ; \mathrm{p}=.01\right)$, indígenas $\left(2,33 \times 2,81 ; \mathrm{t}_{(204)}=1,86, \mathrm{p}=.06\right)$, aborígines $(2,55 \mathrm{x}$ 3,$\left.89 ; \mathrm{t}_{(204)}=4,87, \mathrm{p}<.001\right)$, esquimós $\left(2,65 \times 3,25 ; \mathrm{t}_{(204)}=2,07\right.$ $, \mathrm{p}=.03)$ e nigerianos $\left(1,94 \times 2,48 ; \mathrm{t}_{(204)}=2,20, \mathrm{p}=.02\right)$.

No caso da hipótese 3 , observou-se que o acréscimo da representação pictórica produziu uma mudança significativa em relação à avaliação da distância social. Em relação à representação mental dos grupos sociais, algumas interpretações condizentes com os resultados podem ser apresentadas. Uma delas sugere que a imagem pode reforçar os estereótipos negativos a respeito das categorias sociais diferentes daquela dos percebedores. Os teóricos da memória social tradicionalmente sustentam que um dos fatores que permite um acesso mais fácil às representações armazenadas na memória de longo prazo é a estereotipicalidade da informação. Assim, uma vez ativados, os estereótipos fornecem uma estrutura ou esquema conceitual a partir do qual os estímulos são interpretados. Ora, sabe-se que alguns destes estímulos podem ser congruentes com o esquema conceitual, enquanto outros não. Assim, na medida em que as informações pictóricas se ajustam às representações armazenadas na memória de longo prazo, pode-se esperar um acréscimo na visão estereotipada e, consequientemente, a imposição de uma maior distância social. Ao se assumir que a codificação na memória de longo prazo após a ativação dos estereótipos é diferente no caso das representações que confirmam ou que sejam incongruentes com a representação da categoria alvo armazenada na memória (Macrae, Stangor e Milne, 1994), pode-se esperar, no primeiro caso, não apenas um processamento mais rápido da informação (algo que a pesquisa aqui relatada não considerou), como também a exigência de um menor esforço cognitivo, o que proporcionará mais facilidade na utilização de informações confirmatórias, no caso, as fotografias que se ajustam às representações estereotipadas do grupo alvo armazenadas na memória de longo prazo.

Os resultados obtidos no teste da hipótese 3 são bastante claros no sentido de indicar, portanto, um efeito importante do acréscimo de uma fotografia quando comparada à avalia- ção realizada exclusivamente através de rótulos verbais. Algumas conseqüências destes resultados, sobretudo no plano metodológico, serão apresentadas nas conclusões deste trabalho.

\section{Hipótese 4}

Nesse caso, os resultados sugerem que os participantes residentes em cidades de dimensões mais acanhadas tenderão a impor uma maior distância social em relação às categorias sociais avaliadas. Os resultados obtidos através da análise da variância indicam claramente esta tendência, pois apenas em duas categorias eles não se adequaram à hipótese 4.

Um primeiro elemento que chama atenção na Tabela 4 é a semelhança nos resultados apresentados pelos participantes das cidades de Juiz de Fora e de Vila Velha. Das 12 categorias sociais incluídas no estudo, encontrou-se uma diferença significativa exclusivamente na categoria judeus, onde se observou uma maior intolerância por parte dos residentes de Vila Velha do que a encontrada entre os residentes em Juiz de Fora $\left(2,50 \times 1,52 ; \mathrm{t}_{(87,14)}=3,26 ; \mathrm{p}=.002\right)$, não se observando diferenças significativas em relação a qualquer uma das outras 11 categorias.

Em contrapartida, nota-se uma diferença muito grande em relação à avaliação da distância social, quando se compara a resposta dos participantes das cidades de Juiz de Fora e de Vila Velha, com aquelas apresentadas pelos participantes residentes na cidade de Além Paraíba. Neste caso, observase, na Tabela 4, que os resultados demonstram um índice mais acentuado de preconceito por parte dos residentes desta última cidade, com exceção do caso dos jogadores de futebol, em que não se observou diferença digna de nota na avaliação dos participantes das três cidades, e dos norte-americanos, onde foi encontrada uma diferença significativa entre os participantes de Vila Velha e de Além Paraíba (1,82 x 2,09; $\mathrm{t}$ $\left.{ }_{(123,6)}=2,11 ; \mathrm{p}=.036\right)$, sem que, no entanto, pudesse ser observada qualquer diferença na avaliação por parte dos residentes de Juiz de Fora e Além Paraíba $\left(\mathrm{t}_{(144)}=1,28, \mathrm{p}=.20\right)$. Com exceção destes dois casos, a avaliação das 10 categorias sociais restantes apresentou a mesma tendência, ou seja, as avaliações realizadas pelos participantes residentes nas cidades de Juiz de Fora e de Vila Velha foram muito semelhantes entre si e bem mais tolerantes em relação às categorias sociais retratadas no estudo do que a avaliação feita pelos residentes na cidade de Além Paraíba.

No caso da hipótese 4 , os resultados indicam com clareza o efeito do contexto no qual o percebedor se encontra inserido. Dentre os vários elementos contextuais (Lawrence \& Leather, 1999), o papel desempenhado pelo tamanho da cidade em que o percebedor habita parece exercer um efeito considerável. Os percebedores das cidades de menor porte tendem a avaliar o alvo de uma forma bem mais estereotipada do que os moradores das cidades de maior porte.

\section{Conclusões}

Os resultados obtidos indicam claramente a diferença na avaliação das diversas categorias sociais. Algumas, por uma 
Tabela 4

\begin{tabular}{|c|c|c|c|c|}
\hline \multirow[t]{2}{*}{ Categoria social } & \multicolumn{2}{|c|}{ Médio porte } & \multirow{2}{*}{$\begin{array}{l}\text { Pequeno porte } \\
\text { Além Paraiba }\end{array}$} & \multirow[t]{2}{*}{ sig } \\
\hline & Juiz de Fora & Vila Velha & & \\
\hline futebol & 1,49 & 1,67 & 1,76 & n.s \\
\hline japonês & 1,64 & 1,77 & 2,38 & $* *$ \\
\hline alemão & 1,52 & 1,72 & 2,70 & * \\
\hline americano & 2,09 & 1,82 & 2,51 & n.s. \\
\hline nigeriano & 1,62 & 1,77 & 3,38 & $*$ \\
\hline indigena & 1,99 & 2,33 & 3,56 & * \\
\hline argentino & 1,90 & 2,12 & 3,33 & * \\
\hline judeu & 1,52 & 2,50 & 3,48 & * \\
\hline esquimó & 2,52 & 2,40 & 4,09 & * \\
\hline aborigine & 2,85 & 2,67 & 4,32 & + \\
\hline muçulmano & 2,75 & 2,83 & 4,76 & $\star$ \\
\hline punk & 3,11 & 3,27 & 4,20 & $* *$ \\
\hline
\end{tabular}

Nota: * $<.00 \mathrm{t} ; * *<05$

série de razões, são muito bem avaliadas, enquanto outras são consideradas indesejáveis e, ao que parece, os avaliadores fazem o possível para mantê-las à distância. Na tentativa de determinar se as duas formas de representação do conhecimento, por meio do significado e das imagens, interferem nesta avaliação, foram apresentados indicadores que o acréscimo de uma fotografia à apresentação dos estímulos mediante o rótulo verbal proporcionou diferenças significativas no plano estatístico apenas no caso das categorias que se diferenciam nitidamente no plano físico do padrão do membro prototípico da cultura dos participantes do estudo. Além disso, embora não se tenha encontrado qualquer interação no plano estatístico entre o tipo de representação e as dimensões da cidade em que os avaliadores habitavam, constatouse que os participantes residentes na cidade de porte mais reduzido tenderam a impor uma maior distância social em relação aos membros da categoria alvo, fossem eles apresentados exclusivamente por meio de rótulos verbais ou mediante os rótulos verbais em conjunto com imagens fotográficas.

Além disso, os resultados deste trabalho fornecem alguns elementos para a reflexão sobre os métodos de investigação adotados nos estudos contemporâneos sobre os estereótipos. Uma parcela substancial das pesquisas atuais sobre o processo de estereotipização se sustenta em uma metodologia em que se apresentam primings semânticos, geralmente rótulos com o nome de várias categorias sociais, avaliando-se em seguida o efeito desta apresentação sobre o processamento da informação realizado pelo participante do experimento. Esta estratégia, no entanto, não se encontra imune a críticas, sendo uma das principais aquela compatível com o entendimento de que tal forma de investigação justificar-se-á apenas nas circunstâncias em que se admita uma semelhança de natureza entre pessoas reais e rótulos verbais (Macrae \& Bodenhausen, 2000). Ocorrendo esta equivalência, a adoção dessa estratégia de investigação será justificada; caso contrário, torna-se necessário o aperfeiçoamento dos métodos de investigação dos estereótipos. Uma das principais evidências apresentadas neste trabalho é a de que, pelo menos no caso da avaliação de categorias sociais marcadamente distintas no plano da aparência física, a mera apresentação de uma fotografia em acréscimo ao rótulo verbal parece ser suficiente para desencadear um processo que tende a aumentar de forma significativa a ativação e a aplicação dos estereótipos e, conseqüentemente, a distância social. Isto significa, portanto, que não é possível postular uma equivalência total entre pessoas reais e rótulos verbais. Um fator encontrado na literatura, o problema das múltiplas categorizações, favorece esse entendimento (Gardner, Macyntire \& Lalonde, 1995). Desta forma, se um participante for avaliar, por exemplo, um nigeriano simplesmente através do rótulo verbal, ele disporá apenas das inúmeras representações mentais evocadas pelo significado da palavra. Se, no entanto, a este rótulo verbal for acrescida uma informação pictórica, ele deverá considerar, além das representações mentais evocadas, o fato da fotografia apresentar uma pessoa concreta do gênero masculino, de etnia negra, na faixa etária dos 40 anos, vestindo trajes tipicamente africanos e com um sorriso amigável no rosto. Todas essas representações são ativadas ao mesmo tempo e isto pode ser um fator de contradições e confusões, sendo necessário postular a existência de um processo inibitório capaz de determinar qual a representação que predominará e quais serão inibidas. Dentre os três fatores tradicionalmente apresentados na literatura capazes de indicar o predomínio de uma categoria sobre as outras, dois deles, um perceptual, a saliência da categoria, e um outro cognitivo, a freqüência da acessibilidade das representações na memória, são especialmente importantes no estudo aqui relatado.

Em decorrência da impossibilidade de se postular a equivalência entre um rótulo verbal e uma pessoa real, o horizonte parece apontar para a necessidade de buscar novos recursos que aliem a sofisticação metodológica encontrada nos experimentos contemporâneos sobre os estereótipos com a apresentação de estímulos que simulem cada vez mais as condições em que os percebedores se encontram com pessoas reais. Certamente, por razões diversas, nem sempre se pode esperar que um experimentador disponha de pessoas reais que sirvam como alvo para a avaliação dos participantes. Atualmente, os recursos oferecidos pelos computadores, 
especialmente no plano da multimídia, parecem indicar um caminho a ser seguido pelos psicólogos sociais dedicados à investigação dos estereótipos, uma vez que eles proporcionam a possibilidade de tornar a apresentação do alvo do estereótipo muito mais realista, ou pelo menos, bem mais semelhante à realidade que a apresentação de um simples rótulo verbal ou mesmo de uma fotografia estática.

\section{Referências}

Anderson. J. (2000). Cognitive psychology and its implications. New York: Worth. Brauer, M. (2001). Intergroup perception in the social context: the effects of social status and group membership on perceived out-group homogeinety and ethnocentrism. Journal of Experimental Psychology, 37, 15-31.

Brigham, J. (1971). Ethnic stereotypes. Psychological Bulletin, 76(1), 15-38.

Brown, R., \& Turner, J. (1989). Interpersonal and intergroup behaviour. In J. Turner \& H. Giles (Orgs.), Intergroup Behaviour (pp. 33-65). Oxford: Basil Backwell.

Eysenck, M., \& Keane, M. (1994). Psicologia cognitiva. Um manual introdutório. Porto Alegre: Artes Médicas.

Fiske, S. (1998). Stereotyping, prejudice, and discrimination. In D. Gilbert, S. Fiske \& G. Lindzey (Orgs.), The handbook of social psychology (vol. 2, $4^{\underline{a}}$ ed., pp. 357-411). Boston: McGraw-Hill.

Gardner, R.C., Macintyre, P., \& Lalonde, R. (1995). The effects of multiple social categories on stereotyping. Canadian Journal of Behavioral Science, 27, 4.

Gaskell, G., \& Fraser, C. (1990). The social psychological study of widespread beliefs. In C. Fraser \& G. Gaskell (Orgs.), The social psychological study of widespread beliefs (pp. 3-23). Oxford: Clarendon.

Gilbert, G. M. (1951). Stereotype persistence and change among college students. Journal of Personality and Social Psychology, 46, 245-254.

Hamilton, D., Stroessner, S., \& Driscoll, D. (1994). Social cognition and the study of stereotyping. In P. Devine, D. Hamilton \& T. M. Ostron (Orgs.), Social cognition: impact on social psychology (pp. 291-321). San Diego: Academic Press.

Hamilton, D., \& Trolier, T. K. (1986). Stereotypes and stereotyping: an overview of cognitive approach. In J. F. Dovidio \& S. L. Gaertner (Orgs.), Prejudice, discrimination, and racism (pp. 127-162). Orlando: Academic Press.

Hilton, J., \& Von Hippel, W. (1996). Stereotypes. Annual Review of Psychology, 47, 237-271.

Karlins, M., Coffman, T. L., \& Walters, G. (1969). On the fading of social stereotypes: studies in three generation of college students. Journal of Personality and Social Psychology, 13, 1-16.
Katz, D., \& Braly, K. (1933). Racial stereotypes in one hundred college students. Journal of Abnormal and Social Psychology, 28, 280-290.

Lawrence, C., \& Leather, P. (1999). Stereotypical processing: the role of environmental context. Journal of Environmental Psychology, 19, 383-395.

Leyens, J-P., Yzerbyt, V., \& Schadron, G. (1994). Stereotypes and social cognition. London: Sage.

Lippman, W. (1922). Public Opinion. New York: Harcourt Brace.

Macrae, C. N., \& Bodenhausen, G. (2000). Social cognition: thinking categorically about others. Annual Review of Psychology, 51, 93-120.

Macrae, C. N., Bodenhausen, G., Milne, A., \& Calvini, G. (1999). Seeing more than we can know: visual attention and category activation. Journal of Experimental Psychology, 35, 590-602.

Macrae, C. N., Stangor, C., \& Hewstone, M. (1996). Stereotypes and stereotyping. New York: Guilford.

Macrae, C. N., Stangor, C., \& Milne, A. (1994). Activating social stereotypes: a functional analysis. Journal of Experimental Social Psychology, 30, 370-389.

McCauley, C., \& Stitt, C. (1978). An individual and quantitative measure of stereotypes. Journal of Personality and Social Psychology, 36, 929-940.

Messick, D., \& Mackie, D. (1989). Intergroup relations. Annual Review of Psychology, 40, 45-81.

Morgan, G., \& Griego, O. (1998). Easy use and interpretation of SPSS for Windows. Answering research questions with statistics. Mawhaw: Lawrence Erlbaum.

Oakes, P., Haslam, S., Morrinson, B., \& Grace, D. (1995). Becoming an ingroup: Reexamining the impact of familiarity on perceptions of group homogeneity. Social Psychological Quarterly, 58, 52-61.

Sherman, J. (1996) Development and mental representations of stereotypes. Journal of Personality and Social Psychology, 70, 1126-1141.

Stangor, C. (2000). Volume overview. In C. Stangor (Org.), Stereotypes and prejudice: essential readings. Philadelphia: Psychology Press.

Stangor, C., \& Schaller, M. (1996) Stereotypes as individual and collective representations. In C. N. Macrae, C. Stangor \& M. Hewstone (Orgs.), Stereotypes and stereotyping (pp. 3-37). New York: Guilford.

Wyer, R., \& Srull, T. (1986). Human cognition in its social context. Psychological Review, 93, 322-359.

Yzerbyt, V., Rocher, S., \& Schadron, G. (1997). Stereotypes as explanation: A subjective essencialistic view of group perception. In R. Spears, P. Oakes, N. Ellemers \& S. A. Haslam (Orgs.), The social psychology of stereotyping and group life (pp. 20-50). Oxford: Blackwell.

Zebrowitz, L. (1996). Physical appearance as a basis of stereotyping. In C. N. Macrae, C. Stangor \& M. Hewstone (Orgs.), Stereotypes and stereotyping (pp. 79-120). New York: Guilford.

1 Trabalho parcialmente apresentado no Congresso Interamericano de Psicologia, julho de 2001, Santiago, Chile.

2 Foi apresentada exclusivamente uma única foto para cada categoria social. O critério para a seleção da foto foi o de que o exemplar representado na fotografia, sempre do sexo masculino, deveria se aproximar bastante do padrão estereotipado que se esperaria encontrar no grupo em questão.

Marcos Emanoel Pereira, doutor em Psicologia Social pela Universidade Federal do Rio de Janeiro, é Professor Adjunto do Departamento de Psicologia da Universidade Federal da Bahia, BA.

Fernanda de Oliveira Ferreira, Aretha Henrique Martins e Cleciane Morosino Cupertino são estudantes do Curso de Graduação em Psicologia da Universidade Federal de Juiz de Fora, MG.

Endereço para correspondência: Marcos Emanoel Pereira, Praça Igaratinga, 106, Bloco I, Condomínio São Marcos, Pituba, 41830-300, Salvador, BA. E-mail: emanoel@terra.com.br. 